\title{
HISTÓRIAS DE UMA OBESA: A TEORIA DOS POSICIONAMENTOS E A (RE)CONSTRUÇÃO DISCURSIVA DAS IDENTIDADES
}

\author{
Claudia Almada Gavina da Cruz* \\ Liliana Cabral Bastos** \\ Pontifícia Universidade Católica do Rio de Janeiro \\ Departamento de Letras \\ Rio de Janeiro, RJ, Brasil
}

\begin{abstract}
Resumo: Trata-se de um estudo de cunho etnográfico orientado pelo paradigma de pesquisa interpretativista realizado a partir de uma entrevista individual não estruturada gravada em áudio em uma ONG para atendimento a grandes obesos na cidade do Rio de Janeiro. Amparadas pela teorização dos posicionamentos discursivos que preconiza a transitoriedade dos sentidos, temos como objetivo observar as construções identitárias de uma grande obesa por meio da análise das histórias que conta durante uma entrevista realizada com ela por uma das autoras deste trabalho. Dada a compreensão contemporânea sobre o corpo que tem conferido ao individuo obeso um lugar social de estigma, verifica-se como tal situação vai sendo ratificada ou contestada durante o fazer interacional por meio das posições discursivas aceitas elou refutadas pelos interagentes num movimento que sugere o potencial transformador da linguagem.
\end{abstract}

Palavras-chave: Corpo. Obesidade. Estigma. Posicionamento. Construção identitária.

\section{INTRODUÇÃO}

Proposta inicialmente por Davies e Harré (1990) na psicologia social, a teoria dos posicionamentos tem se mostrado um ferramental bastante produtivo na investigação das construções identitárias que emergem numa interação discursiva ${ }^{1}$. Embora o conceito venha sendo rediscutido e aprofundado por diferentes estudiosos (BAMBERG, 1997; DE FINA, 2013; entre outros) desde sua criação, cabe a Harré e seu grupo o mérito de ter salientado o aspecto dinâmico de nossas identidades - por eles chamadas de self ${ }^{2}$ - como desdobramento das histórias nas quais nos envolvemos cotidianamente.

\footnotetext{
Doutoranda em Estudos da Linguagem. Mestre em Linguística Aplicada. Email: claudia.almada3@gmail.com.

** Professora Associada, Doutora em Linguística. Email: lilianacbastos@gmail.com. Agradeço ao CNPq pelo apoio obtido por meio da bolsa de Produtividade (no. 307202/2012-7).

${ }^{1}$ Note-se o fato de que todo o volume 1 da revista Narrative Inquiry (2013) consiste em trabalhos onde o construto de posicionamento é apresentado como uma via de análise para as identidades narrativas com foco interacional e discursivo (DEPPERMAN, 2013 p. 2). No Brasil, tal teorização também vem sendo adotada em investigações sobre as construções identitárias. Vide, por exemplo, Paula (2003), Cruz (2004), Taveira (2012), entre outros.

2 No modelo de Davies e Harré (1990), o termo self é enfocado em sua dimensão discursiva e interacional, sendo, portanto, por nós aqui compreendido como equivalente à noção de identidades dentro de uma perspectiva processual.
} 
Abre-se, assim, um caminho de análise para as interações discursivas que agrega os estudos identitários e os estudos das narrativas, inserindo-os numa perspectiva dinâmica, fundada na percepção de que os interagentes estão continuamente se localizando em relação uns aos outros e a um macrocontexto no qual estão inseridos. Ou seja, a compreensão que temos sobre quem somos (ou acreditamos ser) no mundo social emerge de um constante movimento de reivindicar, aceitar e refutar posições no discurso, o que, segundo Davies e Harré (1990), se contrapõe ao modelo dos papéis sociais para a compreensão daquilo que dizemos/fazemos no encontro com o outro. Isso se dá porque a teorização desses autores não preconiza a existência de posições anteriores à interação, mas que a interação é em si um conglomerado de posições que vão tecendo ad infinitum uma teia discursiva que é, ao mesmo tempo, produto e produtora de sentidos.

Por tornar relevante o caráter precário e não cristalizado dos sentidos, o construto de posicionamentos parece-nos um caminho promissor na investigação aqui apresentada. Isís, 21 anos, frequentadora de uma ONG para atendimento a grandes obesos, foi entrevistada individualmente na sede da instituição, na zona norte do Rio de Janeiro, no $2^{\circ}$ semestre de 2013. Nesse local, fundado por uma ex-obesa com o objetivo de ajudar pessoas em situação semelhante àquela que vivenciara, acontecem reuniões semanais conduzidas por uma nutricionista e um professor de educação física. É nessas ocasiões que emergem as histórias sobre o que significa ser obeso nas mais variadas situações da vida cotidiana, o que nos motivou a investigar as construções identitárias de pessoas nessa situação.

Solicitada a contar histórias sobre sua condição de obesa numa entrevista individual conduzida por uma das autoras deste artigo, Ísis relata a sua entrevistadora situações de preconceito e exclusão que sofre em diferentes ocasiões sociais. Como já imaginado antes mesmo da análise dos excertos, percebemos que suas construções identitárias estão orientadas pela não adequação a um padrão corporal socialmente valorizado, o que lhe causa angústia e sofrimento. Assim, os relatos de Ísis trazem situações em que uma característica individual - sua obesidade - é percebida como "uma fraqueza, uma desvantagem" (GOFFMAN, 1963, p.12), o que acaba por ameaçar o sucesso das interações sobre as quais discorre. Tal perspectiva nos conduziu à teorização goffmaniana sobre o estigma, como veremos adiante. Porém, optamos por debater as diferenças individuais que desencadeiam preconceito à luz de processos sociais mais abrangentes que validam determinadas formas de ser em detrimento de outras.

Portanto, norteadas pela teorização dos posicionamentos discursivos e de uma perspectiva histórica sobre a construção da diferença, desenvolvemos uma investigação qualitativa de inspiração etnográfica no intuito de investigar o modo como Ísis se constrói socialmente como obesa nas histórias que emergem na interação com sua entrevistadora. Ademais, tentamos também observar se - e até que ponto - essa construção se reorganiza na interação em questão. Ou seja, investigamos aqui de que forma as interações discursivas podem funcionar como arenas para a contestação de sentidos cristalizados sobre os sujeitos sociais.

Os dados foram gravados em áudio e transcritos com base no modelo Jefferson (ver LODER, 2008) com simplificações. 
Proposto inicialmente por Davies e Harré (1990), o conceito de posicionamento tem sua origem no marketing e se refere a estratégias de comunicação que permitem que alguém "coloque" seu produto entre os concorrentes. Esse uso do termo "posicionar", por sua vez, se reporta à linguagem militar no sentido de "tomar uma posição", "colocar-se contra o inimigo" (VAN LANGENHOVE; HARRÉ, 1995).

Nas Ciências Sociais, foi usado primeiramente por Hollway (1984) no estudo da construção das subjetividades nas relações heterossexuais e é a esse uso que a maioria dos autores faz referência quando da abordagem de tal conceito. Hollway propõe o uso da noção de posições no discurso para observar direitos e deveres conversacionais de homens e mulheres em grupos mistos.

Ao propor o conceito, a autora busca explicar por que as mulheres falam menos, quando em companhia dos homens, e mais quando num grupo composto apenas por mulheres $^{3}$. Além disso, ela observa que num grupo composto exclusivamente por mulheres, há maior quantidade de fala total do que num grupo de homens (VAN LANGENHOVE; HARRÉ, 1995). Segundo a autora,

Os discursos disponibilizam posições para serem tomadas pelos sujeitos. Essas posições são em relação a outras pessoas. Assim como o sujeito e o objeto de uma frase...homens e mulheres se localizam em relação um ao outro através dos sentidos que um certo discurso disponibiliza. (HOLLWAY, 1984 p. 236 apud VAN LANGENHOVE; HARRÉ, 1995, p.362). ${ }^{4}$

Quanto à origem do termo, Deppermann (2013) associa a noção de posicionamentos ao conceito de "posições de sujeito" apresentado em Foucault (2008[1969]), quando o autor propõe a noção de "modalidades de enunciação". Em linhas gerais, tal conceito destaca que o discurso não é a expressão verbal de um sujeito único, mas de um somatório de posições tomadas por alguém quando tem a palavra. Ou seja,

[...] as diversas modalidades de enunciação, em lugar de remeterem à síntese ou à função unificante de um sujeito, manifestam sua dispersão: nos diversos status, nos diversos lugares, nas diversas posições que pode ocupar ou receber quando recebe um discurso, na descontinuidade dos planos de onde fala. Se esses planos estão ligados por um sistema de relações, este não é estabelecido pela atividade sintética de uma consciência idêntica a si, muda e anterior a qualquer palavra, mas pela especificidade de uma prática discursiva. (FOUCAULT, 2008[1969], p. 61, grifos do autor).

A influência foucaultiana na teorização dos posicionamentos também aparece tematizada em Tirado e Gálvez (2007), que comentam a importância da noção de discurso e sua circulação, apresentados em Foucault (2008[1969]), para a compreensão

\footnotetext{
${ }^{3}$ Embora não concordemos com essa percepção da autora, sua investigação aparece aqui em função de se tratar do uso inaugural do termo, segundo diferentes estudiosos dos posicionamentos discursivos.

${ }^{4}$ As traduções presentes nesse artigo são de responsabilidade das autoras.
} 
do conceito proposto por Harré e seus colaboradores. Isso se dá especialmente porque Foucault ressalta o vínculo entre o que é dito e a ordem social onde estão presentes as condições de produção de uma enunciação que são imanentes ao encontro e, consequentemente, passíveis de constante revisão. Tal perspectiva certamente orienta a proposta dos posicionamentos quando seus teóricos afirmam, por exemplo, que "o discurso deve ser entendido como um uso institucionalizado da língua" (DAVIES; HARRÉ, 1990, p.45), pois a força daquilo que é dito reside não nas palavras em si, mas num conjunto de relações que determinam seu "significado social".

A nosso ver, tal debate destaca a sócio-história do uso da linguagem, pois aquilo que se diz está marcado, ou orientado, por um conjunto de compreensões sobre o que pode ou não ser dito num certo lugar e num certo momento histórico. Entretanto, essa peculiaridade da circulação do discurso não implica adequação a um estado de coisas, como se houvesse aceitação passiva de certas restrições às enunciações. Ao contrário, Foucault (2008[1969]) aponta que tais enunciações entram numa "ordem de batalhas e lutas" (FOUCAULT, 2008[1969], p.177), onde se confrontam interesses diferentes. Além disso, o autor ressalta serem justamente essas forças sociais diversas que instauram a ambiência para a geração de novos sentidos. No intuito de ilustrar os movimentos de fricção envolvidos no uso do discurso, Tirado e Gálvez (2007) usam, a nosso ver de forma bastante propícia, a metáfora dos movimentos tectônicos para dar conta da emergência das enunciações como resultado de erupções. O discurso irrompe, portanto, de um embate produtivo e é justamente essa proposta que subjaz à teoria dos posicionamentos.

Segundo Deppermann (2013), a importância do estudo seminal de Davies e Harré para os estudiosos do discurso se deve ao fato de terem sido os primeiros a ressaltar as atividades de posicionamento como principal lugar da produção discursiva do self e a relacionar esse fenômeno à narratologia. Embora não utilizem o termo "narrativa", os autores trabalham com a noção de que aprendemos sobre nós mesmos e sobre o mundo em função de nossa inserção em múltiplas linhas de história que discursivamente disponibilizam posições para as pessoas ocuparem e acabam por organizá-las em categorias. Ao aprender sobre essas categorias ao longo de nossas vidas, iremos nos afiliar a algumas em detrimento de outras, nos comprometendo emocionalmente com aquelas com cujo ponto de vista nos identificamos. Além disso, os autores afirmam que esse processo nos leva a organizar um sistema de valores morais informado pela categoria com a qual estamos comprometidos (DAVIES; HARRÉ, 1990). Isso se dá porque "Ao falar ou agir a partir de uma posição, as pessoas estão trazendo à situação particular suas histórias como seres subjetivos, ou seja, a história de alguém que já esteve em múltiplas posições e se envolveu em diferentes formas de discurso." (DAVIES; HARRÉ, 1990, p. 48).

A correlação entre a produção discursiva do self e as linhas de história também é destacada por De Fina (2013), quando ressalta a importância da teoria dos posicionamentos para uma mudança de foco na compreensão das identidades narrativas

\footnotetext{
${ }^{5}$ No presente estudo, os termos 'história' e 'narrativa' serão usados de forma intercambiável, pois interessa-nos a dimensão do ato de contar como oportunidade de negociação de sentidos entre sujeitos, na qual se dão suas construções identitárias.
} 
que vinham tradicionalmente problematizando o narrador como origem e fim dos trabalhos identitários. Segundo a autora, "as reflexões e teorizações sobre posicionamentos foram fundamentais [...] para modelos mais dinâmicos nos quais as identidades são vistas como construídas em diferentes níveis e em negociação com outros participantes [...] (DE FINA, 2013, p.42). Nesta investigação, por exemplo, os relatos de Ísis sobre sua condição de obesa estão polifonicamente articulados com as inúmeras histórias nas quais ela esteve localizada ao longo de sua existência. Essas histórias entrelaçadas informam a compreensão que ela tem sobre si e a orientam na interação com sua entrevistadora num locus também alimentado por uma profusão de discursos a respeito da obesidade.

Embora a perspectiva de articulação micro/macro tenha norteado os teóricos dos posicionamentos desde a proposição desse conceito, Harré e seus colaboradores enfrentam críticas por não terem apresentado um modelo analítico que de fato desse conta de tal articulação. Assim, autores mais recentes vêm reelaborando as noções apresentadas por aqueles estudiosos. Segundo De Fina (2013), o construto de posicionamentos tem sido objeto de reformulações e adaptações teóricas que o fazem hoje um "pouco diferente da maneira como foi originalmente concebido" (DE FINA, 2013, p. 41). Além disso, a autora acrescenta que interpretações mais contemporâneas sobre o conceito pretendem oferecer uma visão sobre o processo que leve em conta, por exemplo, a compreensão dos participantes sobre o momento interacional.

Dentre as reelaborações mencionadas anteriormente, interessa-nos mais especificamente o trabalho de Bamberg (1997). Envolvido com o estudo das narrativas com foco naquilo que "o falante busca alcançar pelo ato de narrar" (BAMBERG, 1997, p. 335), o autor toma o modelo de Davies e Harré (1990) como ponto de partida. Isso se dá porque, embora a noção de posicionamentos não tenha sido proposta exclusivamente para tratar das narrativas, Bamberg (1997) reconhece as contribuições desse construto teórico para os estudos na área, pois se trata de um modelo que "tenta usar estrategicamente as noções de enredo e linhas de história” (BAMBERG, 1997, p. 336).

$\mathrm{Na}$ tentativa de viabilizar a operacionalização do conceito como ferramenta de análise com dados empíricos de narrativas, Bamberg (1997) propõe, então, um modelo que observa três níveis de ocorrência dos posicionamentos:

Nível 1: Como os personagens são posicionados com relação uns aos outros dentro dos eventos reportados? Nesse ponto, o analista deverá observar as escolhas linguísticas do narrador a fim de perceber a localização dos personagens no mundo da história e sua construção como vítimas, algozes, agentes etc. Trata-se, em linhas gerais, de se compreender o assunto de uma história (BAMBERG, 2002);

Nível 2: Como o falante se posiciona levando em conta a audiência? Aqui o interesse da análise se volta para o momento da interação, pois é quando nos "perguntamos por que uma história é contada em um dado ponto da interação" (BAMBERG, 2002, p.157) e que efeito o narrador "está tentando alcançar com a história". Ou seja, a audiência numa narrativa adquire o status de participante num evento discursivo.

Nível 3: Como os narradores se posicionam para si próprios? Trata-se do momento em que o analista deve deslocar seu foco de observação para os discursos 
socialmente disponíveis aos quais os falantes se reportam ao contar uma história. $\mathrm{Ou}$ seja, esse nível de análise busca articular o assunto da história (nível 1) e a ordem interacional (nível 2) com uma certa ordem moral em que os falantes se apoiam para elaborar uma resposta, ainda que provisória, para a pergunta “quem sou eu?". Trata-se de uma tentativa por parte do narrador de definir o seu self para si e para os outros.

Tanto Bamberg (2002) quanto De Fina (2013) ressaltam que os posicionamentos de níveis 1 e 2 são complementares e sobrepostos, pois uma mesma escolha linguística pode servir simultaneamente a um propósito mais referencial (nível 1) ou interacional (nível 2). Além disso, Bamberg (2002) nos alerta de que o self, que se constituiria através do nível 3, não deve ser compreendido como dado individual que resiste a mudanças sócio-históricas, mas como uma construção discursiva produzida "na relação de co-autoria entre os participantes" (BAMBERG, 2002, p.159) de uma interação. Há aqui, a nosso ver, uma sobreposição dos níveis 2 e 3, pois cremos que a noção de self também seja balizada pelo momento interacional.

Parece-nos que a proposta de Bamberg claramente aponta para a importância da articulação entre o nível micro da interação e um macrocontexto, ou seja, a sóciohistória do encontro. No intuito de melhor compreender essa dimensão macro a respeito da obesidade, passemos a considerar o conceito de Estigma (1963) e a correlação dessa teorização com uma discussão sobre o processo de individualização do corpo na contemporaneidade.

\section{ESTIGMA E CORPO}

A preocupação com a natureza dos encontros sociais caracteriza-se como o grande fio condutor da obra de Goffman. Nesse sentido, ele define os encontros sociais como "empreendimentos em orientação conjunta" (GOFFMAN, 2002 [1964] p.18), em que ocorre "um esforço da parte de todos para atravessar a ocasião e todos os eventos imprevistos e não intencionais que podem colocar os participantes sob uma luz indesejável" (GOFFMAN, 2012[1967], p. 46).

É justamente o foco no encontro social e na situação social dos interagentes que serve como pano de fundo para a proposição de diferentes conceitos goffmanianos, tais como "face", "footing", entre outros, dos quais destacamos aqui a noção de "estigma". Esse conceito visa a dar conta da instabilidade e da incerteza que se instalam quando um dos participantes é incapaz de satisfazer a regras e expectativas que garantem o sucesso da interação. Em função de tais expectativas que orientam os interagentes, eles acabam por estabelecer categorias para as pessoas atribuindo-lhes uma certa identidade social ${ }^{6}$.

Surge daí a ideia de Estigma proposta por Goffman não para falar de um atributo em si, mas da maneira como alguém é percebido quando está aquém de uma categorização ou estereótipo prévio, numa determinada situação. Embora o autor comente a possibilidade de que alguém seja reclassificado positivamente ao longo de

\footnotetext{
${ }^{6}$ Goffman usa o termo "identidade social" como equivalente aos atributos que se espera de um indivíduo em função da categoria que ele, ou ela, representa. Para uma noção processual das identidades, vide discussões adiante.
} 
uma interação, tal situação não é seu foco de interesse. Ele enuncia, então, a seguinte definição sobre o que pretende observar: "Um estigma é, então, na realidade, um tipo especial de relação entre atributo e estereótipo, embora eu proponha a modificação desse conceito, em parte porque há importantes atributos que em quase toda a nossa sociedade levam ao descrédito." (GOFFMAN, 2012[1963], p. 13).

Embora destacando o aspecto relacional de seu conceito ao teorizar sobre normalidade e estigma como "perspectivas geradas em situações sociais" (GOFFMAN, 2012[1963], p.149), Goffman parece-nos bastante interessado nos ditos "atributos que levam [...] ao descrédito", acima mencionados. Segundo o autor, são esses atributos que provocam manobras por parte dos interagentes para que a situação social seja bemsucedida. Daí, parece-nos haver um claro foco no indivíduo como origem do desconforto que pode vir a ameaçar a paz do encontro social. Além disso, Goffman coloca a resolução dos conflitos nas mãos dos interagentes, não correlacionando o malestar interacional a outras questões sociais que alimentam os atritos.

Essa perspectiva individualista é apontada por Monteiro et al. (2013) como uma limitação do conceito goffmaniano de estigma, pois argumentam que a atribuição de responsabilidade ao portador do estigma desconsidera as desigualdades sociais que são, ao mesmo tempo, causa e resultado dos embates onde discurso e poder estão intimamente articulados. Segundo as autoras, a análise das situações de estigma deve recuperar "os processos sociais que configuram o sentido de si ao sujeito e à sua corporalidade.” (MONTEIRO et al., 2013, p. 72).

Essa crítica nos parece bastante relevante porque abre um debate necessário sobre a produção social das desigualdades e da exclusão, o que, por sua vez, pode contribuir para redimensionar a visão negativa que certos grupos de estigmatizados têm sobre si. No caso da obesidade, a adoção de uma perspectiva mais ampla na análise das situações de estigma poderia colocar em xeque algumas percepções do senso comum como, por exemplo, a identificação do obeso como alguém de caráter fraco e sem força de vontade (HALPERN; MANCINI, 2002). Não se trata aqui de negligenciarmos o sujeito, mas sim de evitarmos uma análise unilateral e, portanto, reduzida sobre processos sociais mais amplos.

Ademais, acreditamos que a adoção de um olhar individualista na percepção sobre o estigma pode levar o analista do discurso a maximizar seu foco na interação em detrimento do nível macro de uso do discurso, como se os interagentes estivessem localmente articulando uma agenda de significados pré-definidos segundo sua "vontade própria". É justamente por reconhecer a fundamental importância da localização do aqui e agora interacional dentro de uma rede mais ampla de significados que optamos pelo ferramental dos posicionamentos, conforme já debatido. Entretanto, em vez de meramente apontarmos as críticas à teorização goffmaniana, tão atenta à figura do estigmatizado, cremos que mais profícuo é o debate sobre o que gerou tal perspectiva individual sobre a diferença.

Para tanto, passemos à discussão sobre como o corpo foi historicamente perdendo seu vínculo com o coletivo e adquirindo a noção de individualidade com a qual operamos hoje. A nosso ver, esse deslocamento fez do corpo uma espécie de propriedade individual, o que coloca o foco no sujeito como origem e responsável por sua condição física. 
Diferentemente da correlação que atualmente se faz entre o corpo e a individualidade, os tempos pré-modernos foram marcados por uma indefinição de limites entre os corpos e as vidas dos membros de um certo grupo social. Seja pelas ameaças concretas representadas pelas constantes epidemias, guerras, entre outras dificuldades, ou por uma visão sobre o humano como inserido no mundo físico, o corpo, segundo Lupton (1998), era "poroso" ou aberto. Ou seja, não estavam claras as fronteiras entre o exterior e o interior dos corpos que se abriam em orifícios por onde extravasavam, vez por outra, os fluidos que o compunham.

Como desdobramento da percepção do corpo físico, também a noção de "self" que se impunha no período pré-moderno era bem menos independente e autônoma do que aquela com a qual operamos hoje. Desse modo, desde a infância, as pessoas eram socializadas como parte de um todo - a família ou a comunidade - cuja manutenção dependia de um esforço coletivo. Além disso, também por influência da visão da época sobre o corpo físico, acreditava-se que os sentimentos resultavam igualmente de fluidos que deveriam ser equilibrados para a manutenção do bem-estar emocional das pessoas.

Embora a noção sobre as emoções como estando correlacionadas aos fluidos corporais tenha persistido até o início da era moderna, muitos historiadores apontam as mudanças sociais ocorridas nos recém-criados Estados europeus como marco em direção ao culto de um corpo "civilizado". Tal objetivo se cumpriria com disciplina e controle e se fundava na noção de agência de indivíduos autônomos que se relacionavam na composição da sociedade e que tinham a capacidade de domar seus impulsos mais mundanos. Sob influência da reforma protestante, o corpo passa a ser regido pela racionalidade de um sujeito capaz de conter suas emoções por meio do uso de seu livre arbítrio.

Por ocasião da Revolução Industrial até meados do século XVIII, a noção de individualismo e autorregulação se tornaram mais difundidas em função, provavelmente, de mudanças sociais advindas da urbanização que fez com que as pessoas passassem a se relacionar com grupos bem mais numerosos do que acontecia nas antigas comunidades. Aprofunda-se a separação entre o corpo e as emoções, que passam a ser vistas como sentimentos invisíveis possuídos pelas pessoas que são "proprietárias" de seus corpos. Configura-se, assim, a imagem do homem moderno civilizado representado pelo conquistador europeu a quem se contrapunha a imagem dos povos coloniais, construídos como grotescos, selvagens ou, ainda, infantis, dada a sua incapacidade de controlar seus instintos mais primordiais.

O foco na noção de indivíduo trazida pela modernidade instalou uma lógica dualista na qual o corpo é percebido "como uma posse, um atributo, um outro, um alter ego" (LE BRETON, 2012, p.10), o que, a nosso ver, coloca imensa responsabilidade

\footnotetext{
${ }^{7}$ Há de se ter em mente que estamos aqui traçando um panorama de sociedades ocidentais individualistas, pois representam o contexto cultural em que se insere essa investigação. Le Breton (2012) destaca a existência de sociedades tradicionais que seguem um modelo de vida comunitária, nas quais "o estatuto da pessoa subordina-se ao coletivo" (LE BRETON, 2012, p. 30) e o corpo é o elo que une cada elemento do grupo e faz do indivíduo parte de uma ecologia única.
} 
nas mãos de cada um sobre o que fazer com sua propriedade. Como corolário, o autor destaca a atenção que as ciências sociais vêm dedicando ao corpo como produtor de sentidos, ou seja, o corpo como lugar onde está representado aquilo que aprendemos com nosso grupo cultural, mas que pode ser também território de manifestação de um desejo individual de se diferenciar do outro, de marcar-se para comunicar algo sobre si.

Parece-nos que a perspectiva individualista anteriormente esboçada alimenta noções como vontade e livre arbítrio, que informam diferentes percepções a respeito da corporeidade e apontam para o compromisso de cada um com o corpo que habita. Desse modo, observamos que muito das discussões sobre a obesidade hoje - assim como de outras condições corporais resultantes da bulimia, da vigorexia, entre outras - têm privilegiado o indivíduo como origem e responsável por sua condição, em detrimento da problematização do coletivo. Nesse sentido, Contreras e Gracia (2011) discutem a tendência observada nos discursos médicos e da saúde pública a convencer as pessoas sobre a importância de adotarem dietas que "evitem riscos/enfermidades para a saúde, a controlarem a si mesmas, a serem responsáveis consigo mesmas..." (CONTRERAS; GRACIA, 2011, p. 357)

Essa lógica individualista pode levar o analista a negligenciar o que se diz socialmente sobre o corpo, assim como o impacto desses discursos sobre o indivíduo obeso. Não se trata aqui de um movimento de desresponsabilização desse indivíduo, mas de uma tentativa de localizá-lo numa ordem discursiva dentro da qual todos operamos e na qual se identificam as batalhas e disputas de significados amplamente discutidas em Foucault, entre outros. Assim, as discussões sobre alimentação - aí inseridos temas como dieta, transtornos alimentares e obesidade, por exemplo - não devem estar desvinculados da cultura, onde são levadas em conta as "condições econômicas, culturais e políticas [...] estruturadas por um capitalismo de consumo que afeta a tudo e a todos [...]" (CONTRERAS; GRACIA, 2011, p. 326).

No sentido de recuperar tais significados, passemos, então, à análise dos dados partindo da perspectiva dos posicionamentos discursivos.

\section{A ENTREVISTA OU "HISTÓRIA É O QUE MAIS TEM"}

Os dados que aqui analisamos foram gerados numa entrevista individual realizada por Claudia - uma das autoras deste artigo - quinze dias após uma entrevista com foco no grupo que ocorreu durante a reunião semanal dos frequentadores da ONG. Naquela ocasião, Ísis - a entrevistada - introduziu espontaneamente o tema do bullying que sofrera na escola em virtude da obesidade. Decidida a investigar a questão mais a fundo, Claudia estabelece esse tópico logo no início da entrevista individual, o que pode ter orientado Ísis a abordar outros tantos momentos em que esteve em posição desfavorável em função de sua condição corporal. Assim, a interação enseja o surgimento de narrativas em cascata que tratam do preconceito contra o obeso em diferentes situações sociais e do impacto que isso lhes causa. As convenções usadas nas transcrições que se seguem encontram-se no anexo. 
"Eu já fui chamada de monstra dentro de casa"

\begin{tabular}{|c|c|c|}
\hline $\begin{array}{l}01 \\
02 \\
03 \\
04 \\
05\end{array}$ & fsis & $\begin{array}{l}\text { eu já ouvi coisas assim horriveis, tanto de familia, como de } \\
\text { pessoas na rua. eu ouvi já: dentro de casa que:eu num la passar da } \\
\text { porta se eu continuasse comendo do jeito que eu tava comendo (.) eu } \\
\text { já: fui chamada de monstra dentro de casa, de tão gorda que eu } \\
\text { tava eu era um monstro }\end{array}$ \\
\hline $\begin{array}{l}06 \\
07\end{array}$ & Claudia & $\begin{array}{l}\text { vocé diz-vocé acha que as pessoas te diziam isso prá: tipo te dar } \\
\text { um alerta ou tipo pra- só pra zoar mesmo }\end{array}$ \\
\hline 08 & Isis & [ tem ] \\
\hline 09 & Claudia & [que que]cê acha? \\
\hline 10 & fsis & dentro da minha casa, é uma maneira errada de tentar ajudar(.) \\
\hline 11 & Claudia & entendi. \\
\hline $\begin{array}{l}12 \\
13 \\
14 \\
15\end{array}$ & fsis & $\begin{array}{l}\text { usava uma palavra errada, negativa pra dar animo, sendo que: eu } \\
\text { até tava conversando com o presbitero da minha igreja, que ele } \\
\text { também é obeso e ele é muito grande, ele é maior do que eu e ele } \\
\text { tava falando que com ele também é a mesma coisa }\end{array}$ \\
\hline 16 & Claudia & hum hum \\
\hline $\begin{array}{l}17 \\
18 \\
19 \\
20\end{array}$ & fsis & $\begin{array}{l}\text { que as pessoas falam "ah, tá gordo, tá enorme, tá isso" porque } \\
\text { acha que vaí ajudar e năo vaí (.) hoje eu percebi que eu tenho } \\
\text { depressăo ' eu fuí diagnosticada com depressão (.) por causa de } \\
\text { tudo isso que eu vivi, assim é muito preconceito junto }\end{array}$ \\
\hline
\end{tabular}

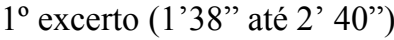

Esse trecho, que aparece logo nos primeiros minutos de conversa entre Ísis e Claudia, representa uma espécie de sumário da entrevista como um todo, pois anuncia o modo como a entrevistada localiza os obesos como pessoas socialmente desprestigiadas ao longo da conversa. Embora não se trate aqui de um estudo sobre narrativas dentro de uma perspectiva laboviana - tanto que usamos os termos "narrativa" e "história" de forma intercambiável - acreditamos que a noção de ponto narrativo proposto por Labov e Waletsky (1967) como "a razão de ser da narrativa" (BASTOS, 2005) nos seja útil para compreender a motivação do relato de Ísis. Assim, parece-nos que o ponto de todas as histórias contadas por ela é o mesmo: posicionar o obeso como um estigmatizado.

O estabelecimento do ponto narrativo, por sua vez, sustenta a função avaliativa, apontada por Labov e Waletsky (1967) como uma das características das narrativas, juntamente com sua função temporal. Passemos, então à análise das histórias propriamente ditas à luz da teoria dos três níveis de posicionamentos que, segundo Bamberg (1997), resulta justamente de uma tentativa de harmonização das duas funções das narrativas apontadas pelo modelo laboviano.

Iniciamos nossa análise pelo nível 1, ou seja, etapa em que o foco é a construção dos personagens da história com relação uns aos outros. $\mathrm{Na}$ verdade, trata-se de duas pequenas histórias - Ísis em família e a conversa com o presbítero - que se articulam e se alimentam e que serão, portanto, tratadas simultaneamente. Na primeira história, percebemos que ela claramente se apresenta como vítima do preconceito "tanto de família como de pessoas da rua" em função de sua obesidade. Isso se reflete, por exemplo, na estrutura sintática usada por Ísis, em que se verificam duas situações onde ela aparece como sujeito da passiva - "fui chamada de monstra" e "fui diagnosticada com depressão" - o que corrobora seu posicionamento como alguém desprovido de agência. Observe-se que o segundo uso da voz passiva vem como um reparo ao uso da voz ativa "eu tenho depressão", o que sugere a situação subalterna de Ísis que extrapola 
o mundo da história e a posiciona no mundo interacional (nível 2 de posicionamento) como refém de uma situação. Embora Ísis traga uma outra história na qual narra uma conversa com outro indivíduo obeso - o presbítero de sua igreja -, esse personagem aparece como uma espécie de alter ego seu, alguém que não chega a adquirir existência própria e que serve apenas para ratificar o relato de sofrimento que ela faz. Parece-nos que mesmo o uso da fala relatada em discurso indireto, "ele tava falando que com ele é a mesma coisa", não é suficiente para trazer o presbítero à cena, mas suas palavras apenas corroboram a opinião de Ísis sobre as dificuldades encontradas pelos grandes obesos no mundo social.

Cremos que esse procedimento sirva como sustentação ao posicionamento que Ísis busca construir tanto no mundo da história quanto no mundo interacional, na tentativa de delinear o preconceito que experimenta cotidianamente, que dará o tom à primeira parte da nossa entrevista e motivará a atitude da entrevistadora no $3^{\circ}$ excerto.

\section{"Você fica com a obesidade tanto na sua cabeça, que ela não sai de você"}

\begin{tabular}{|c|c|c|}
\hline $\begin{array}{l}01 \\
02 \\
03 \\
04 \\
05 \\
06 \\
07 \\
08 \\
09 \\
10 \\
11 \\
12\end{array}$ & fsis & $\begin{array}{l}\text { ấ eu tava até falando com elas que eu tinha perdido peso e tal, } \\
\text { ấ elas ficaram bem felizes, aí eu falei "mas ainda năo faz } \\
\text { diferença", "clą:ro que faz diferença", porque tem aquela coisa } \\
\text { também do emagrecer e se olhar no espelho, eu năo me vejo mais } \\
\text { magra do que eu tava há um mês, mas eu sei que eu tô por causa das } \\
\text { roupas, porque você fica co:m a obesidade tanto na sua cabeça, } \\
\text { que ela não sai de você, ela sai do seu corpo, mas num sai da sua } \\
\text { cabeça (.) in:- questăo do bullyinq, eu já fui pro parque } \\
\text { aquático, subi num - tava na boia- piscina de onda (.) ai o menino } \\
\text { falou assim, é: virou pra namorada dele e falou assim "olha lá, } \\
\text { uma boia em cima de outra boia, num sei como é que ainda num } \\
\text { afundou" }\end{array}$ \\
\hline 13 & Claudia & gratuitamente? \\
\hline 14 & Isis & de olhar, é \\
\hline 15 & Claudia & que coisa \\
\hline 16 & Isis & de olhar e julgar (.) é:o olhar e julgar, eu já ouvi \\
\hline 17 & Claudia & pessoas que nem te conheciam, nem [convivem com você] \\
\hline 18 & fsis & [nunca me viram, nunca me viram] \\
\hline 19 & Claudia & isa, meu Deus \\
\hline
\end{tabular}

\begin{tabular}{|l|l|l|l|l|}
\hline 20 & tsís & mas eu acho que pior, é quando vem de quem vocế gosta, das pessoas
\end{tabular}

\begin{tabular}{|c|c|c|}
\hline $\begin{array}{l}20 \\
21 \\
22 \\
23\end{array}$ & Isis & $\begin{array}{l}\text { mas eu acho que pior, é quando vem de quem vocé gosta, das pessoas } \\
\text { que convivem com vocé (.) e tal. é, eu, por exemplo, é tinha: num } \\
\text { era um namorado, era mais ou menos, eu năo gostava dele, mas ele } \\
\text { falou que sempre gostava de mim, sempre gostou. só que eu num } \\
\text { acreditava que ele gostava de mim por causa do meu corpo, que ele } \\
\text { era muito bonito, ele malhava e tal. af: passou um tempo, eu } \\
\text { comecei a gostar dele, a gente começou a namorar(.) so que quando } \\
\text { foi- ele foi na minha casa conhecer minha familia, só que quando } \\
\text { foi pra conhecer a familia dele ele falou "Isis, desculpa, mas năo } \\
\text { vai dar (.) num vai dar pra gente, pra eu te levar na minha casa, } \\
\text { pra eu te assumir como namorada e tal" aí eu perguntei "por que?" } \\
\text { ai ele "porque: meus amigos num văo aceitar, eu vou ser motivo de } \\
\text { chacota, motivo de piada". isso acabou: comigo, eu fiquei arrasada } \\
\text { eu fiquei muito tempo sem falar com ele, a gente voltou a se falar } \\
\text { agora (.) só que mesmo assim eu falei pra ele que eu num quero } \\
\text { aproximaçăo com ele, porque ele me magoou de um jeito que pouca } \\
\text { gente consegue me magoar }\end{array}$ \\
\hline 37 & Claudia & e na verdade ele que tinha começado a gostar de você primeiro \\
\hline 38 & Isis & lé \\
\hline 39 & Claudia & [meu Deus ] \\
\hline $\begin{array}{l}40 \\
41\end{array}$ & Isis & $\begin{array}{l}\text { ele falou "eu gosto muito de você, mas- assim- no dia que você } \\
\text { emagrecer, quem sabe". ai eu falei pra ele "no dia que eu } \\
\text { emagrecer, eu num vou querer você(.) porque eu vou querer uma } \\
\text { pessoa que tivesse me aceitado do jeito que eu era antes" }\end{array}$ \\
\hline
\end{tabular}
$2^{\circ}$ excerto (9'43" até 11 ' 50 ”) 
Essa sequência foi extraída de um momento em que Ísis conta para sua entrevistadora sobre sua boa relação com as primas, apesar dos preconceitos que sentia por parte dos demais membros da família. Nesse momento, ela relata a reação positiva dessas primas quando lhes conta sobre sua perda de peso, o que, entretanto, não apaga, ou melhor, não minimiza a desilusão amorosa que ela menciona em seguida.

Com relação ao nível 1 de posicionamento, que focaliza o mundo da história, observamos que Ísis traz à cena diferentes personagens cujos pontos de vista ela habilmente manipula por meio do uso discurso direto. Segundo Bauman (1986), essa técnica funciona como um recurso performático que, a nosso ver, corrobora a noção de nossas identidades como um fazer. Assim, Ísis não é uma vítima antes de sua interação com Claudia, mas constrói-se como vítima no aqui e agora interacional por meio de suas escolhas e estratégias linguísticas. Ou seja, seu posicionamento na interação com sua entrevistadora encontra suporte na maneira como vai paulatinamente se posicionando e sendo posicionada discursivamente na história.

Quanto aos personagens trazidos à cena, observamos que ocupam diferentes status no mundo da história - o que se revela, por exemplo, na quantidade de fala atribuída a cada um. Além disso, eles parecem servir a diferentes funções. Enquanto as primas aparecem como uma espécie de apoio emocional quando posicionam Ísis positivamente por estar conseguindo perder peso, o menino do parque aquático e o namorado são seus antagonistas no mundo da história (nível 1 de posicionamento) e despertam a solidariedade da entrevistadora no mundo interacional (nível 2 de posicionamento). Logo, a perplexidade de Claudia percebida nas linhas 13, 15, 17 e na repetição da interjeição "meu Deus" (linhas 19 e 39) sugerem que ela aceita na interação o posicionamento de vítima que Ísis reivindica no mundo da história. Trata-se de um exemplo do entrelaçamento dos níveis 1 e 2 de posicionamento, pois a história relatada gera um efeito na interação. Além disso, o modo como a entrevistada é posicionada desfavoravelmente no mundo da história, tanto pelo menino quanto pelo namorado, baliza a compreensão que ela tem sobre si no mundo social. Ou seja, o nível 3 de posicionamento se organiza em contraponto com o nível 1.

Embora semelhantes na posição de antagonistas a Ísis, observamos que o menino do parque aquático e o namorado diferem quanto ao tipo de reação que a entrevistada menciona. Assim, diferentemente do que acontece no caso do menino, ela resolve reagir à repulsa demonstrada pelo rapaz (linhas 41-43), embora recorrendo a um futuro hipotético ("no dia que eu emagrecer") para um revide. Acreditamos se tratar de uma das primeiras situações de não aceitação, por parte de Ísis, de uma posição a ela atribuída, apesar de se declarar "arrasada" (linha 32) com a situação.

Quanto à atitude do namorado, acreditamos exemplificar sua negação a vivenciar aquilo que Goffman (2012 [1963]) chama "difusão do estigma". Segundo o autor, pessoas muito íntimas do estigmatizado costumam experimentar uma atitude negativa por parte da sociedade, como uma forma de estigma indireto, o que explica o temor do rapaz de se tornar motivo de "chacota e piada" (linha 32). Além disso, trata-se de uma ocasião em que fica bastante clara a inserção do que se diz localmente numa ordem discursiva mais ampla, onde circulam os discursos que estigmatizam o obeso e ameaçam também estigmatizar quem se relaciona com essa pessoa. Portanto, podemos questionar se o estigma está no obeso ou nas relações sociais que ele tem de gerenciar pois é justamente no social que se dá o confronto de sentidos quando uma enunciação é produzida (FOUCAULT, 2008[1969]). 


\section{"Eu sinto também que eu tô dando um pouco de trabalho assim, pra eles em casa"}

\begin{tabular}{|c|c|c|}
\hline $\begin{array}{l}01 \\
02 \\
03 \\
04\end{array}$ & f́sis & $\begin{array}{l}\text { e eu sei que vou ter que fazer a minha familia sofrer muito dentro } \\
\text { de casa pra poder se adaptar a mim, por exemplo, nesse processo de } \\
\text { reeducaçăo alimentar , a minha familia já tá sofrendo muito } \\
\text { [(poderia)]- }\end{array}$ \\
\hline $\begin{array}{l}05 \\
06\end{array}$ & Claudia & $\begin{array}{l}\text { [ah mas eu] não sei se tá sofrendo, às vezes também tá ganh- a } \\
\text { familia também tá ganhando, (.) } \\
\text { [né, fsis] }\end{array}$ \\
\hline $\begin{array}{l}07 \\
08 \\
09\end{array}$ & fsis & $\begin{array}{l}\text { porque eu escuto assim minha irmã-minha irma é muito magrinha (.) } \\
\text { ai eu escuto minh- minha irma falando assim, minha irmă tem onze } \\
\text { anos(.) "poxa, mãe, eu queria um bolo" ai minha măe "năo, năo vou } \\
\text { fazer, clara", porque elas năo conversam na minha frente, mas eu } \\
\text { escuto elas conversar. }\end{array}$ \\
\hline $\begin{array}{l}13 \\
14 \\
15 \\
16\end{array}$ & Claudia & $\begin{array}{l}\text { Ah, mas eu acho sabe o quê, Ísis, que a gente também tem uma: uma } \\
\text { visăo assim de que: ter a despensa cheia de biscoito, ter bolo na } \\
\text { casa, num sei o que (voz estilizada), isso é que é se alimentar } \\
\text { bem, năo é. ce sabe que eu- }\end{array}$ \\
\hline $\begin{array}{l}17 \\
18\end{array}$ & fsis & $\begin{array}{l}\text { năo é, mas é que você tirar de uma criança biscoito essas coisas } \\
\text { assim- }\end{array}$ \\
\hline 19 & Claudia & ah: [mas tem outras] coisas boas \\
\hline 20 & fsis & [eu sei que faz] bem pra ela, eu sei que faz bem pra ela- \\
\hline 21 & Claudia & né? o tanto de fruta que cês já devem tá consumindo na ca:sa- \\
\hline 22 & Isis & é(.) fruta >graças a Deus< [ela come bem] \\
\hline 23 & Claudia & [de suco \\
\hline 24 & Isis & nte f-jela sente falta \\
\hline 25 & Claudia & acho que [ela \\
\hline
\end{tabular}

\begin{tabular}{|c|c|c|}
\hline $\begin{array}{l}26 \\
27\end{array}$ & Ísis & $\begin{array}{l}\text { por exemplo, minha mãe começou a dar dinheiro pra ela pra ela } \\
\text { poder comprar na rua (.) pra pelo menos matar um pouquinho a } \\
\text { vontade dela, porque minha mãe também falou "num vou restringir } \\
\text { ela demais, porque ela já faz a dieta do engorda, né, ela tem onze } \\
\text { anos é alta(.) e pesa } 29 \text { quilos, ela é muito magrinha.. ela já fez } \\
\text { nutricionista, agente fazia a mesma nutricionista, eu pra perder } \\
\text { peso e ela pra ganhar. aí e a nutricionista falava pra minha mãe } \\
\text { "é, pra você é uma situação bem complicada"- }\end{array}$ \\
\hline 34 & Laudia & ter que lidar com essas duas situações \\
\hline $\begin{array}{l}35 \\
36\end{array}$ & Ísis & $\begin{array}{l}\text { balancear a alimentação(.) pra uma ganhar e a outra perder (.) tá } \\
\text { difícil (.) ih, náo é só, é, >por exemplo< acho que causa um } \\
\text { estresse também no casamento da minha mãe (.) porque minha mãe é } \\
\text { separada, mora com outra pessoa que é o pai da minha irmã e ele } \\
\text { também gosta dessas coisas assim, >por exemplo< ele tava falando } \\
\text { esses dias pra minha mãe "poxa, vânia, faz lasanha", aí minha mãe } \\
\text { falou "eu não vou fazer lasanha(.) porque é massa, massa vai fazer } \\
\text { a Ísis querer comer mais, e tal", mas aí eu falei pra minha mãe } \\
\text { "ta-também não posso falar pra vocês 'nâo comam", eu tenho que } \\
\text { aprender a lidar com isso", porque não vai ser a vida inteira que } \\
\text { vai ter, um dia eu vou, gra-um dia, em nome de Jesus, eu vou } \\
\text { arrumar um emprego, tô atrás de estágio, eu vou ter que almoçar na } \\
\text { ru:a, eu vou ter que aprender a lidar com o que tem lá, num vai } \\
\text { te:r- }\end{array}$ \\
\hline 49 & Laudia & os poucos você vai entrando nesse- [nessa dosagem], né \\
\hline $\begin{array}{l}50 \\
51 \\
52 \\
53 \\
54\end{array}$ & Ísis & $\begin{array}{l}\text { ter que balancear, com o que tem, com pouco, vou ter que saber } \\
\text { fazer escolhas (.), fez lasanha, eu não como arroz, feijáo que nem } \\
\text { comia antigamente e um pedacinho de lasanha, como só a lasanha, } \\
\text { vou ter que aprender a conviver, ou eu abro mão da lasanha e } \\
\text { almoço (.) aí minha mãe falou, mas mesmo assim, ela fica meio } \\
\text { assim de fazer e causar tentação em casa(.) então eu sinto também } \\
\text { que eu tô dando um pouco de trabalho assim, pra eles em casa }\end{array}$ \\
\hline
\end{tabular}

$\left(3^{\circ}\right.$ excerto $-23^{\prime} 01$ até $\left.26^{\prime}\right)$

CRUZ, Claudia Almada Gavina da; BASTOS, Liliana Cabral. Histórias de uma obesa: a teoria dos posicionamentos e a (re)construção discursiva das identidades. Linguagem em (Dis)curso - LemD, Tubarão, SC, v. 15, n. 3, p. 367-384, set./dez. 2015. 
Esse excerto veio como resposta à pergunta feita pela entrevistadora quanto aos planos de Ísis de se submeter à cirurgia bariátrica, pois alguns dos pacientes da ONG têm o objetivo de emagrecer investindo numa mudança de estilo de vida e na reeducação alimentar. Sua resposta é negativa, já que, após a cirurgia, ela avalia que terá de se submeter a severas restrições alimentares que envolverão esforços tanto de sua parte quanto de sua família. Para ilustrar tais esforços, ela apresenta narrativas em cascata (sobre a irmã, sobre o casamento da mãe e sobre um futuro emprego) em que se posiciona como a causa de um problema. Nesse sentido vale observar a construção sintática da primeira frase, em que ela se coloca em primeira pessoa como agente do sofrimento da família, o que, provavelmente, ecoa sua situação de desprestígio social enunciada nos excertos anteriores. Ao construir-se como a causa de um problema, Ísis parece operar dentro da lógica do estigma como marca individual, o que coloca sobre o indivíduo estigmatizado a responsabilidade por sua discriminação.

Entretanto, diferentemente do que observamos nos trechos anteriores, parece haver aqui, pela primeira vez na entrevista, uma tentativa por parte da entrevistadora de relativizar o olhar negativo que Ísis tem sobre si e posicioná-la diferentemente. Tal percepção se apoia em diferentes marcas discursivas presentes na interação como, por exemplo, sobreposição e interrupção de falas, maior quantidade de turnos da entrevistadora, o que sugere uma tentativa de intervenção por parte dela no sentido de refutar um posicionamento solicitado pela entrevistada. Assim, em lugar de se solidarizar à posição de vítima que Ísis reivindica no mundo da história - como ocorre no segundo excerto -, Claudia busca desnaturalizar sentidos sobre comer bem num movimento que se inicia na linha 5, quando ela interrompe o turno de Ísis. Tal movimento equivale à proposta feita por Claudia de um novo posicionamento para Ísis no mundo interacional (nível 2) por meio de uma contestação de sua posição no mundo da história (nível 1), o que aponta, novamente, para a interpenetração dos níveis analíticos do modelo de Bamberg (1997).

Os sentidos sobre alimentação com os quais Ísis e Claudia operam estão certamente informados por diferentes discursos que circulam no mundo social a respeito da comida e que atribuem uma valoração àquilo que se come. Ou seja, embora nutrir-se seja uma necessidade humana primária, claro está hoje para a antropologia social que os alimentos estão repletos de significações (CONTRERAS; GRACIA, 2011) construídas por diferentes grupos segundo a região que habitam, a época em que vivem, a classe social a que pertencem etc. Nesse sentido, parece-nos que os significados trazidos por Ísis à interação equiparam uma vida feliz a uma liberdade para a ingestão de alimentos doces, ou seja, trata-se, a nosso ver, da ideia do açúcar como recompensa, o que aparece em diferentes festividades da nossa cultura (a páscoa, o saco de guloseimas nas festas de aniversário, entre outras). Claudia, por outro lado, parece recorrer a sentidos informados pelos discursos do "nutricionalmente correto" e da boa forma, valorizados hoje sobremaneira na mídia (CONTRERAS; GRACIA, 2011). Tal perspectiva claramente aponta para a importância do olhar sobre a cultura e o mundo social na análise das interações, alinhavando o nível 3 de posicionamento às outras duas camadas de análise.

Novamente com relação aos posicionamentos no mundo da história, chama-nos atenção o lugar de vítima construído nesse trecho. Diferentemente dos dois excertos anteriores em que era Ísis quem ocupava essa posição, aparece aqui a figura de sua mãe como aquela sobre quem recai grande parte do sofrimento gerado por sua condição de 
obesa na família. Assim, é a mãe quem tem de lidar com a dificuldade de negar bolo à filha mais nova (linhas 10-11), lasanha ao marido (linhas 40-42), assim como tem de acompanhar as duas filhas com necessidades tão diferentes à nutricionista (linhas 3032). Observe-se que ao relatar a fala da nutricionista em discurso direto (linha 33) e , ainda, reforçar a ideia de dificuldade com o uso do advérbio de intensidade ("bem"), Ísis busca explicitar o "ônus" que sua mãe tem de gerenciar.

Em contrapartida, a entrevistada reivindica nesse excerto a posição de algoz que é, justamente, o que motiva o movimento de reposicionamento organizado pela entrevistadora, já debatido anteriormente. Entretanto, não obstante esse movimento interacional, Ísis não aceita o novo posicionamento proposto por Claudia e fecha o trecho com uma declaração (linhas 56-57) que funciona como paráfrase da ideia com a qual ela abre o excerto.

\section{CONSIDERAÇÕES FINAIS}

Ao propor o conceito dos posicionamentos discursivos, Harré e seu grupo tem como foco a compreensão daquilo que se diz num contexto institucionalizado do uso da língua que atribui lugares prenhes de significação aos sujeitos e àquilo que eles dizem. Ademais, tal teorização busca compreender o que fazemos uns com os outros em nossas interações discursivas, o que certamente se distancia de uma percepção de língua como representação.

Essa dupla perspectiva que acompanha os posicionamentos desde sua proposição continua a orientar o modelo de Bamberg (1997) proposto para operacionalizar o uso daquela elaboração teórica com dados empíricos. Ao propor uma análise dos posicionamentos em três níveis, esse modelo aposta na articulação de uma análise linguística com uma compreensão sobre o mundo social no qual coexistem forças econômicas, políticas e culturais que impactam na nossa compreensão sobre nós mesmos e na forma como nos apresentamos para o outro.

Por acreditarmos na correlação entre o que se diz no aqui e agora interacional e as contingências sócio-históricas nas quais os interagentes circulam, optamos pela teoria dos posicionamentos para compreensão do modo como Ísis se constrói socialmente como obesa. Além disso, buscamos observar até que ponto as construções identitárias por ela reivindicadas eram aceitas ou contestadas internacionalmente.

Primeiramente - e como já imaginávamos antes mesmo da análise - observamos que o discurso de Ísis está pautado por uma posição de pessoa estigmatizada socialmente que claramente experimenta no cotidiano o desconforto interacional tematizado por Goffman (1963). Trata-se de um lugar de desprestígio ao qual ela se reporta num movimento de "default", mesmo quando ela imagina contestá-lo. Por exemplo, quando levanta a hipótese de futuramente desprezar o namorado, ela continua a operar com o significado de que o obeso não tem oportunidades no mundo afetivo, pois Ísis descreve esse futuro como "o dia que eu emagrecer" (excerto 2, linhas 41-42). Além disso, na linha 25 do mesmo excerto, Ísis descreve o namorado como um homem bonito "que malhava e tal". Essa identificação entre beleza e um corpo atlético novamente exclui o obeso da arena das relações amorosas, o que sustenta $o$ posicionamento de desprestígio que Ísis reivindica. 
Entretanto, não obstante esse "default" do lugar do obeso que orienta as construções identitárias de Ísis, a interação parece apontar para novos lugares a serem ocupados. Assim, no movimento da entrevista, a reação de Claudia no terceiro excerto, quando contesta a posição de algoz reivindicada pela entrevistada, pode ter instabilizado algumas certezas de Ísis sobre sua posição de desprestígio como consequência inevitável de sua condição corporal. Ainda que de forma tênue, o terceiro excerto parece frear significados "em cascata" sobre o sofrimento de uma obesa e acenar para uma nova compreensão sobre o espaço que ela ocupa no mundo. Ou seja, trata-se de um momento em que alguém diz para Ísis que as coisas podem não ser bem como ela imaginara.

Logo, parece-nos ter havido na interação um movimento de contestação do lugar em que Ísis se localiza como obesa e, concomitantemente a proposta de um novo status para ela por meio da ação de sua entrevistadora. Acreditamos que esses momentos, embora breves, podem contribuir para a ressignificação de quem somos no mundo social, pois o mesmo discurso que remete o sujeito a uma rede de significados cristalizados é também a via de problematização deles. Fica assim marcada a relevância do olhar analítico sobre as interações discursivas por se tratar de ocasiões em que novas posições podem ser ocupadas e viabilizar outras formas de existir.

\section{ANEXO: CONVENÇÕES DE TRANSCRIÇÃO}

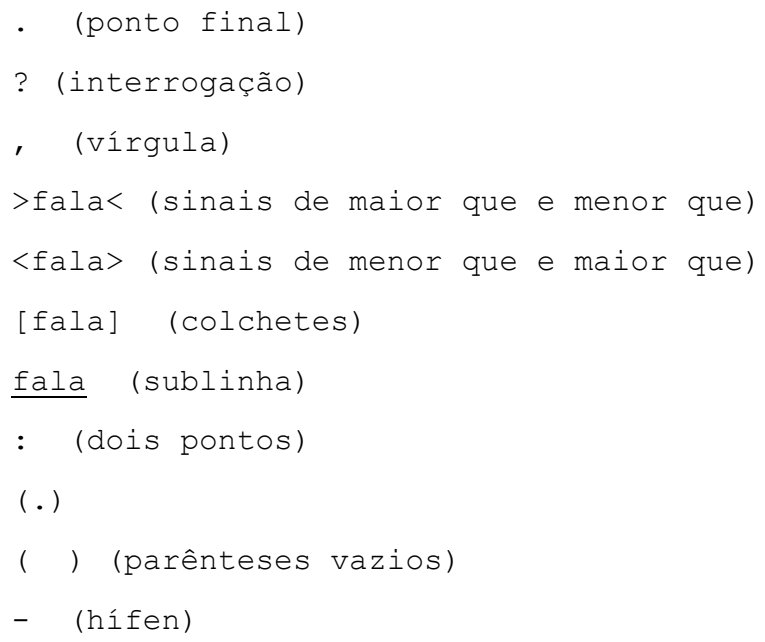

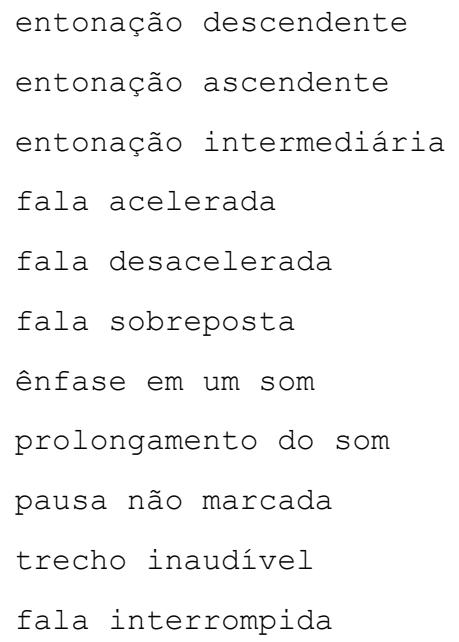

REFERÊNCIAS

BAMBERG, M. Positioning Between Structure and Performance. Journal of Narrative and Life Story, v. 7, n. 1-4, p. 335-342, 1997.

Construindo a masculinidade na adolescência: posicionamentos e o processo de construção da

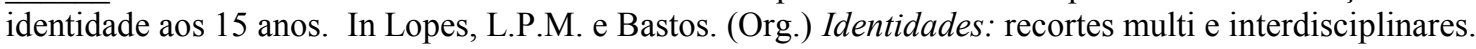
Campinas: Mercado de Letras, 2002.

BASTOS, L. C. Contando estórias em contextos espontâneos e institucionais - uma introdução ao estudo da narrativa. Calidoscópio, São Leopoldo, v. 3, n. 2, p. 74-87, 2005.

BAUMAN, R. Story, performance and event: Contextual studies of oral narrative. Cambridge: Cambridge University Press, 1986. 
CRUZ, C.A.G. Interferindo na construção discursiva da masculinidade hegemônica na escola: uma pesquisa-ação. 2004. 151f. Dissertação (Mestrado em Linguística Aplicada) - Faculdade de Letras, Universidade Federal do Rio de Janeiro, 2004.

CONTRERAS, J.; GRACIA, M. Alimentação, sociedade e cultura. Rio de Janeiro: Editora Fiocruz, 2011.

DAVIES, B.; HARRÉ, R. The discursive production of selves. Journal for the Theory of Social Behaviour, v. 20, n. 1, p. 43-63, 1990.

DE FINA, A. Positioning level 3: connecting local identity displays to macro social processes. Narrative Inquiry, v. 23, n. 1, p. 40-61, 2013. John Benjamins Publishing Company

DEPPERMAN, A. Positioning in narrative interaction. Narrative Inquiry v. 23, n. 1, p. 1-15, 2013. John Benjamins Publishing Company.

FOUCAULT, M. A arqueologia do saber. Rio de Janeiro: Forense Universitária, 2008[1969].

GOFFMAN, E. A situação negligenciada. In RIBEIRO, B.T; GARCEZ, P.M. Sociolinguística Interacional. São Paulo: Edições Loyola, 2002[1964].

Ritual de Interação: Ensaios sobre o comportamento face a face. Petrópolis: Vozes, 2012[1967]. 2012[1963] Estigma: Notas sobre a manipulação da identidade deteriorada. Rio de Janeiro: LTC,

HALPERN, A.; MANCINI, M. C. Manual de obesidade para o clínico. São Paulo: Roca, 2002.

HOLLWAY, W. Gender difference and the production of subjectivity. In J. Henriques, W. Hollway, C. Urwin, C. Wenn; V. Walkerdine (Eds.) Changing the subject: Psychology, social regulation and subjectivity. London: Methuen, 1984. p. 227-263.

LABOV, W.; WALETSKY, J. Narrative Analysis. Oral versions of personal experience. In: J. Helm (Ed.). Essays on the Verbal and Visual Arts (p.12-44) Seattle: University of Washington Press, 1967. [reimpresso em Journal of Narrative and Life History, 7, 1997, 3-38]

LE BRETON, D. A sociologia do corpo. Petrópolis, RJ: Vozes, 2012.

LODER, L. L. O modelo Jefferson de transcrição: convenções e debates. In LODER, L. L.; JUNG, N. M. (Org.). Fala-em-interação social. Introdução à análise da conversa etnometodológica. Campinas: Mercado de Letras, 2008.

LUPTON, D. The Emotional Self. A sociocultural exploration. University of Sydney, Australia: Sage, 1998.

MONTEIRO, S.; VILELA, W.; PEREIRA, C.; SOARES, P. Produção acadêmica recente sobre estigma, discriminação, saúde e Aids no Brasil. In MONTEIRO, S.; VILELA, W. Estigma e saúde: uma relação vital em debate. Rio de Janeiro: Editora Fiocruz, 2013.

PAULA, R.C. Construindo consciência das masculinidades negras em contexto de letramento escolar: uma pesquisa-ação. In: MOITA LOPES, L.P. (Org.) Discursos de identidades: discurso como espaço de construção de gênero, sexualidade, raça, idade e profissão na escola e na família. Campinas, SP: Mercado das Letras, 2003. p.181-208.

TAVEIRA, D.M.O.S. Coé, chegaí: pesquisando a dinâmica da formação de grupos de adolescentes em narrativas de inclusão e exclusão. 2012. 203 f. Tese (Doutorado em Letras) - Programa de Pósgraduação em Letras, Pontifícia Universidade Católica do Rio de Janeiro, Rio de Janeiro, 2012.

TIRADO, F.; GÁlVEZ, A. Positioning Theory and Discourse Analysis: Some Tools for Social Interaction Analysis. FQS Forum: Qualitative Social Research Sozialforschung V. 8, N. 2, May 2007. Disponível em <http://www.qualitative-research.net/index.php/fqs/Article/view/248/547 Acesso em 28 abr. 2015 .

VAN LANGENHOVE; HARRÉ, R. Cultural stereotypes and positioning theory. Journal for the Theory of Social Behavior, v. 24, n. 4, p. 359-372, 1995.

Recebido em: 11/05/15. Aprovado em: 24/10/15 
Title: An obese woman's stories: positioning theory and the discursive (re)construction of identity

Authors: Claudia Almada Gavina da Cruz; Liliana Cabral Bastos

Abstract: Oriented by the interpretive paradigm in social sciences, especially ethnographic work, this article results from the analysis of an individual interview audio recorded in an NGO which assists morbid obese patients in Rio de Janeiro. Taking into account positioning theory and its presuppositions about the transient nature of meaning, we aim at investigating identity construction through the analysis of the stories an obese woman tells during an interview with one of the authors of this article. We argue that the way the body is understood nowadays is responsible for stigma towards fat individuals. In this sense, we have observed how such a situation is ratified or contested by means of discursive positions people take in interaction. We believe this movement is exactly where the transformative potential of language rests.

Keywords: Body. Obesity. Stigma. Positioning. Identity construction.

Título: Historias de una obesa: la teoría de los posicionamientos y la (re)construcción discursiva de las identidades

\begin{abstract}
Autores: Claudia Almada Gavina da Cruz; Liliana Cabral Bastos
Resumen: Este estudio tiene abordaje etnográfico orientado por el paradigma de la investigación interpretativa y fue realizado desde una entrevista individual no estructurada grabada en audio en una ONG para atendimiento a personas obesas en la ciudad de Rio de Janeiro. Considerando la teorización de los posicionamientos discursivos que preconiza el carácter transitorio de los sentidos, el objetivo fue observar las construcciones de identidad de una grande obesa por medio del análisis de las historias que cuenta durante una entrevista realizada por una de las autoras de este trabajo. Dada la comprensión contemporánea sobre el cuerpo que hay conferido al individuo obeso un lugar social de estigma, se verifica cómo esta situación se va a ratificar o contestar durante las interacciones por medio de las posiciones discursivas aceptas u/o refutadas por los interagentes en un movimiento que sugiere el potencial transformador del lenguaje.
\end{abstract}

Palabras-clave: Cuerpo. Obesidad. Estigma. Posicionamiento. Construcciones de identidad. 